\title{
A PRAÇA URBANA - O CASO DO BAIRRO RESIDENCIAL CAMPO BELO EM PIRAPOZINHO-SP
}

\author{
Vanessa Penha, Mayara Pissutti Albano Vieira \\ Universidade do Oeste Paulista - UNOESTE, Curso de Arquitetura e Urbanismo, Presidente Prudente, SP.
}

\begin{abstract}
RESUMO
A praça insere-se na paisagem urbana que é formada por ações tanto naturais como antrópicas, por fatores econômicos, culturais e sociais, e faz parte também dos espaços livres urbanos. A importância da praça deve-se a alguns fatores principais: por muitas vezes, ser a principal opção de lazer urbano, por possibilitar o contato com a natureza (quando possui vegetação) e por proporcionar um espaço de socialização, de trocas de experiências e de integração com o meio urbano. A cidade de Pirapozinho - SP não apresenta muitas praças, e as existentes, concentram-se predominantemente no centro da cidade. Diante de tal situação, o presente trabalho visa a escolher e analisar uma área passiva de receber uma praça no bairro Residencial Campo Belo, na referida cidade, desprovido de espaços públicos de lazer. A metodologia deste trabalho se baseia em pesquisas bibliográficas, documentais e de campo.

Palavras-chave: Paisagem urbana. Praça urbana. Praça brasileira. Bairro Residencial Campo Belo. Pirapozinho
\end{abstract}

\section{THE URBAN SQUARE - THE CASE OF CAMPO BELO RESIDENTIAL IN PIRAPOZINHO-SP}

\begin{abstract}
The square is inserted in the urban landscape which is formed by both natural and anthropic actions, by economic, cultural and social factors, and is also part of urban free spaces. The importance of the square is due to some main factors: it is often the main option for urban leisure, for enabling contact with nature (when it has vegetation) and for providing a space for socialization, exchange of experiences and integration with the urban environment. The city of Pirapozinho - SP does not present many squares, and the existing ones, concentrate predominantly in the city center. Given this situation, the present work aims to choose and analyze an area capable of receiving a square in the Campo Belo residential neighborhood, in the mentioned city, devoid of public leisure spaces. The methodology of this work is based on bibliographical, documentary and field research. Keywords: Urban landscape. Urban square. Brazilian square. Campo Belo residential neighborhood. Pirapozinho
\end{abstract}

\section{INTRODUÇÃO}

A pesquisa que embasou o presente artigo teve como objeto de estudo a praça, que está inserida no contexto da paisagem urbana e, no meio urbano é vista como um espaço livre público, destinado ao lazer e ao convívio da população. 
Os espaços livres urbanos são explicados de maneira simples por Magnoli (2006), como todo espaço livre de edificação, não coberto e que está ligado aos prédios do entorno, às atividades humanas, tanto na forma de espaços de circulação como nas áreas de permanência, sendo a praça, um tipo de espaço livre. Rolnik (1992) diz que, a praça tem sua beleza constituída por sua história, desenho paisagístico e conjunto urbanístico. A integração entre morfologia, estética e apropriação é que permite a formação de praças, como espaços simbólicos, lugares de memória, alma da cidade.

$\mathrm{Na}$ Antiguidade, as cidades se formavam a partir dos seus espaços de convivência. De acordo com Coulanges (1975), pertencer à cidade, ser cidadão, era habitar os lugares de reunião, era compartilhar o culto, participar das assembleias, assistir às festas, acompanhar as procissões, vivenciar os espaços, participando da vida pública. A praça simbolizava a própria cidade, pois era nesse espaço que as atividades cotidianas se desenvolviam.

Nas cidades medievais, a configuração da praça segundo Caldeira $(2007$, p.23) “[...]definiuse pelo contraste do vazio com a densa paisagem, estruturando uma diversidade de espaços: praças de mercado, praça da igreja, praça cívica, praça de entrada, praça central, ou mesmo conjunto de praças". Durante o século XIV, no período inicial do Renascimento, as praças passaram a ser locais públicos utilizados para exaltar monumentos e estátuas e eram geralmente usados para festejos públicos. É nesta época que aparecem pela primeira vez as praças ajardinadas, onde os jardins tinham o objetivo de valorizar a arquitetura existente tanto na praça como em seu entorno, proporcionando embelezamento e ornamentação das cidades.

No período Barroco, Mumford (1982) diz que as praças se caracterizavam por ter determinado vias axiais na estrutura da cidade, e por ser um local onde os eixos viários eram desviados. Ele diz ainda que tinham escalas grandiosas com formas constantemente geométricas e que diferentemente dos espaços fechados das praças renascentistas. Durante o século XIX e XX as cidades passam por intensas mudanças por causa de uma modernidade fortemente influenciada pela cultura europeia visando a transformação da paisagem das cidades com foco na salubridade e igualmente no embelezamento (SILVA, 2008).

Caldeira (2007) aponta a praça contemporânea com o objetivo principal de fazer dos lugares de conexão ou nós, um lugar simbólico, atribuindo características de ponto focal, ou seja: monumentalidade, multifuncionalidade, intercâmbio, lugar de encontro e de expressão e a partir dessas estratégias, reafirma sua vocação de espaço coletivo, reassumindo o papel de principal espaço da cidade.

A cidade de Pirapozinho -SP, se apresenta com poucas praças e mal distribuídas na malha urbana, a maioria concentradas no centro, por isso em alguns bairros este tipo de espaço ou é inexistente ou não apresenta um projeto adequado às necessidades dos moradores. Para tal, a presente pesquisa busca desenvolver pesquisas que possam auxiliar na melhora da condição supracitada.

Sendo assim, têm-se como objetivo o desenvolvimento de diretrizes projetuais para a realização de um futuro projeto urbano em Pirapozinho - SP, mais precisamente no bairro Residencial Campo Belo, o qual é carente de um espaço público condizente com suas necessidades.

\section{METODOLOGIA}

Para alcançar tais objetivos, a metodologia elaborada para este trabalho seguiu a ordem aqui apresentada: a primeira etapa baseou-se em levantamentos bibliográficos, feitos por meio de pesquisa eletrônica de trabalhos livros e periódicos que abordam os principais temas estudados. Na segunda etapa, foi realizado levantamento documental e de campo a fim de se obter material necessário para realização de estudos do terreno escolhido e também de um raio de abrangência de duzentos metros. Forma realizados nesta etapa levantamento de uso e ocupação da área, 
gabarito de altura, equipamentos urbanos próximos, arborização por porte, condições de iluminação e sinalização, dentre outras informações, que geraram subsídios para a proposição das diretrizes projetuais, elaboradas na terceira etapa.

\section{RESULTADOS E DISCUSSÃO}

O importante papel que os espaços livres urbanos desempenham, segundo Weingartner (2008), possibilitam inúmeras atividades, desde a simples circulação de pessoas, uso para a produção de alimentos, abrigo à vida silvestre, encontro de amigos, descanso e realização de exercícios físicos, jogos e outros.

Dentre os espaços públicos urbanos, abordando mais especificamente as praças. Viero $(2009$, p.1) aponta que "a praça pode ser definida, de maneira ampla, como qualquer espaço público urbano, livre de edificações que propicie convivência e/ou recreação para os seus usuários". De Angelis (et. al., 2005) afirmam que para alguns, as praças são locais de bate papo, reencontro e que para outros podem significar trocas de experiências, lazer, meditação ou ainda lugar fundamental da vida social, espaço de encontro, de trocas de palavras e mercadorias.

\section{A PRAÇA NO BRASIL}

A origem das praças brasileiras, para a maioria dos autores, se dá nos primeiros assentamentos do Brasil colônia, entretanto, outros autores consideram as ocupações indígenas com seus costumes e cultura como início desses espaços aqui. E, a partir da origem, a praça brasileira foi sofrendo alterações de acordo com determinadas épocas em sua morfologia, função e uso. As aldeias dos índios eram compostas por cabanas que demarcavam uma grande área central e era nessa área que aconteciam cerimônias e encontros cotidianos. Esse espaço central, a única "praça" local, o qual tinha todas as entradas das cabanas voltadas para si, convidavam as pessoas ao encontro, o que tornava o espaço público (KOHLSDORF, 2002).

De acordo com Perrone (2000) é a partir do processo de colonização no Brasil que esses espaços livres apresentaram duas formas diferentes: uma, nas aldeias e assentamentos indígenas existentes, e outra, nas vilas e cidades implantadas no âmbito urbano. A ocupação territorial portuguesa no Brasil sofreu influências da organização formal das aldeias, conforme Caldeira (2007) nos diz, na arquitetura, as técnicas indígenas foram essenciais para que os portugueses aproveitassem os recursos disponíveis para se estabelecerem.

Robba e Macedo (2003) apontam que os primeiros espaços livres públicos brasileiros foram os adros das igrejas, espaços deixados em frente aos templos e é justamente estes espaços que formaram as primeiras praças. Quanto às praças cívicas, Marx (1980) relata que esses espaços geralmente se caracterizavam por sua localização em frente de prédios públicos importantes e a primeira praça cívica do Brasil, segundo o mesmo autor, foi a Praça Municipal de Salvador. Sobre os jardins, Robba e Macedo (2003) relatam que eram raros nas cidades coloniais brasileiras; apareciam nas propriedades religiosas ou nos quintais das residências, haviam também alguns hortos e jardins botânicos que tinham objetivos comerciais, científicos e de pesquisa da flora nativa. Copiando o modelo europeu de espaços ajardinados, destinados ao uso coletivo e conservando as características dos jardins palacianos, como áreas de contemplação, meditação e passeio, foi implantado, no Rio de Janeiro, o primeiro Passeio Público do Brasil, no final dos anos setecentos.

No século XIX, houve uma rápida consolidação e assimilação da praça ajardinada como padrão de modernidade urbana, assim consolidou-se também o costume de projetar a praça pública, entretanto somente as praças mais importantes ou "mais nobres" receberam tais projetos ou foram reformadas, as restantes eram tratadas como largos ou terreiros, sem qualquer cuidado urbanístico (ROBBA; MACEDO, 2003). 
No século XX, Roberto Burle Marx, rompeu com as escolas tradicionais e iniciou um movimento de valorização da vegetação nativa brasileira, até então desprezada nos projetos paisagísticos (MEDEIROS, 2009). A linha projetual paisagística moderna inicia-se em 1934 com os jardins da Praça de Casa Forte de Burle Marx, em Recife (ROBBA; MACEDO, 2003).

$\mathrm{Na}$ contemporaneidade, é comum encontrar em algumas praças atividades comerciais, como lanchonetes, camelôs, bancas de revistas. Enfim, as praças foram se adequando às necessidades e os espaços foram evoluindo e se aprimorando com os novos elementos e de acordo com o contexto social, econômico e cultural de cada época. Em todos os momentos, o convívio social esteve presente na história da praça brasileira e a vegetação marca presença desde a praça ajardinada até os dias atuais. A partir disto conclui-se que ambos elementos são primordiais para projetar uma praça atualmente: promover o convívio social e o contato com a natureza, sendo assim o projeto desenvolvido apoia-se em ambos pilares.

\section{ÁREA DE ESTUDO}

A área escolhida para estudo localiza-se na cidade de Pirapozinho, situada no oeste do estado de São Paulo. Possui uma população aproximada de 24.700 habitantes, e foi emancipada no ano de 1948 (IBGE, 2010). Portanto, trata-se de uma cidade de porte pequeno e de fundação recente.

Pirapozinho apresenta apenas duas praças, localizadas próximas ao centro e, uma quadra pública de futsal no bairro Santa Edwiges. Sendo assim, trata-se de uma localidade carente de espaços públicos de lazer, justificando, desta feita, a importância de estudos relacionados ao tema, não apenas no local escolhido como objeto de estudo, mas em outros bairros também.

Figura 1. Cidade de Pirapozinho - SP, praças existentes, quadra pública de futsal e área escolhida para estudo

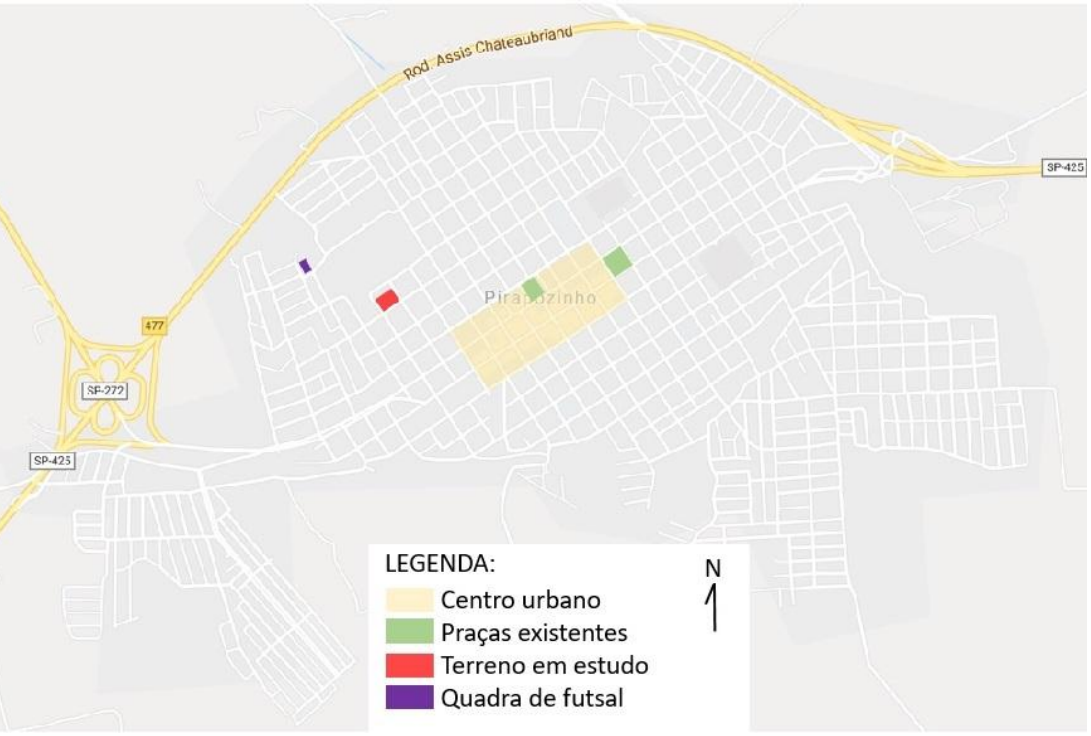

Fonte: Google maps, editado pelos autores, 2018.

O terreno escolhido, é registrado como área de lazer, segundo documentos oficiais da Prefeitura Municipal, contudo, está vazio e sem uso. Localiza-se no bairro Campo Belo, que apresenta como ponto marcante a rápida urbanização, com permanência de vazios urbanos. No entorno do terreno nota-se a presença de um edifício escolar e de uma Área de Preservação Permanente (APP). O acesso principal se dá pela Rua Antenor Ferreira Soares que possui tráfego mediano.

Os estudos de uso e ocupação, realizados durante a pesquisa, mostraram um bairro praticamente todo residencial, com poucos comércios e algumas instituições. $O$ gabarito de altura 
em sua maioria é de apenas um pavimento e o padrão construtivo predominante é a alvenaria. A arborização é mal distribuída e algumas árvores, de grande porte, são completamente inadequadas às calçadas, que por sua vez, possuem pequenas dimensões, cerca de 2,50 m. A sinalização das ruas e iluminação estão em condições precárias.

A seguir serão mostrados os estudos iniciais para o projeto da Praça Urbana em Pirapozinho, com a definição das diretrizes projetuais.

\section{DIRETRIZES PROJETUAIS}

Criar uma área de lazer e recreação com mobiliário diferenciado. Na parte infantil fazer com que este mobiliário sirva de extensão do aprendizado, pensando na relação com o entorno onde existe uma Escola de ensino infantil (até quinto ano) e também priorizar a segurança dessa área, por causa das crianças que podem eventualmente correr para a rua, por exemplo.

Criar uma praça de alimentação com funcionamento noturno, para que esse espaço ofereça atividades em diferentes períodos do dia havendo assim um movimento constante de pessoas e maior sensação de segurança.

Destinar um pequeno espaço para eventos, voltados para atividades locais, do bairro.

Garantir acessibilidade em toda extensão da praça, visto que um espaço público deve atender a todos e possibilitar seu uso sem diferenciação.

Criar um elemento de identidade para a praça, afim de que esta sirva como um ponto de referência dentro do bairro em que será inserida.

Garantir boa iluminação, priorizando por segurança e conforto visual.

Trabalhar o paisagismo de forma interativa, para que as pessoas tenham mais contato com a natureza.

Aproveitar parte murada criando elementos que se integrem com o restante da praça, afim de não torná-la uma barreira física.

\section{CONSIDERAÇÕES FINAIS}

A partir de todas as pesquisas e estudos realizados neste trabalho, concluiu-se a necessidade de um projeto de praça urbana no bairro Residencial Campo Belo de Pirapozinho, o qual é carente de espaços de lazer condizentes com as necessidades da população.

\section{REFERÊNCIAS}

CALDEIRA, J. A praça brasileira: trajetória de um espaço urbano - origem e modernidade. 2007. 432 f. Tese (Doutorado em História) - Universidade Estadual de Campinas, Campinas, 2007.

COULANGES, Fustel. A cidade antiga: estudos sobre o culto, o direito, as instituições da Grécia e de Roma. Trad.José Camargo Leite e Eduardo Fonseca. São Paulo: HEMUS, 1975.

DE ANGELIS, Bruno Luiz Domingues et al. Praças: História, Usos e Funções. Editora da Universidade de Maringá - Fundamentum (15), 2005.

KOHLSDORF, M. A Apreensão da Forma da Cidade. Brasília: Ed. UNB, 1979.

MAGNOLI, Miranda. Espaço Livre: objeto de trabalho. Paisagem ambiente, São Paulo,n.21, 2006 $a, p, 182$.

MARX, Murilo, Cidade Brasileira. Melhoramentos, Ed. Da Universidade de São Paulo,1980. 
MEDEIROS, G. L. Modernidade no jardim: síntese ou dialética das artes? Artepaisagem em Roberto Burle Marx e Waldemar Cordeiro. In: SEMINÁRIO DOCOMOMo, 8., 2009, Rio de Janeiro. Anais... Rio de Janeiro: DOCOCOMO, 2009

MUMFORD, Lewis. A cidade na história suas origens, transformações e perspectivas, Brasília, Editora universidade de Brasília, 1982.

PERRONE, M. B. "A vida nas aldeias dos Tupi da costa" in Viver no Brasil colônia, Revista OCEANOS, n. 42 -abril/junho. Lisboa: CNCDP, 2000.

ROBBA, F; MACEDO, S. Praças brasileiras.2.ed.São Paulo: Editora da Universidade de São Paulo, 2003.

ROLNIK, Raquel. "História Urbana: História na Cidade?". In Fernandes, e Gomes, M. A. de F. Cidade e História. Modernização das Cidades Brasileiras nos Séculos XIX e XX.UFBA, Faculdade de Arquitetura, ANPUR, Salvador, 1992:27-29.

SILVA, Alzilene Ferreira. Cinema na Praça: sociabilidade e modificações das relações de usos em praças na cidade de Salvador-Ba. In: VI Congresso Português de Sociologia. Mundos sociais: saberes e práticas. Universidade Nova de Lisboa, junho de 2008. Número de série 572. Anais, p.19. Disponível em: < http://www.aps.pt/vicongresso/pdfs/572.pdf. >. Acessado em 17 de agosto de 2017

VIEGAS, SILVA, ELALI. Um Oásis Urbano: Dois Estudos das Interações Pessoa-Ambiente na Praça Kalina Maia, Natal/RN. $2014 . \quad$ Disponível em: <http://revistaseletronicas.pucrs.br/ojs/index.php/revistapsico/article/view/17297/pdf_1>. Acessado em 02 de agosto de 2017.

VIERO, V. Praças públicas: origem, conceitos e funções.2009. Disponível em: < http://www.ceap.br/material/MAT1511201011414.pdf >. Acessado em 15 de maio de 2017. WEINGARTNER, G. A construção de um sistema: os espaços livres públicos de recreação e de conservação em Campo Grande, MS .2008. 192 f. Tese (Doutorado em Arquitetura e Urbanismo) Faculdade de Arquitetura e Urbanismo, Universidade de São Paulo, São Paulo, 2008. 